\title{
They are all lies. Even Mother Theresa did it for herself ... ${ }^{1}$
}

\author{
Johan Hattingh and Minka Woermann
}

\begin{abstract}
In this paper we explore the question of what are we trying to achieve in teaching business ethics at undergraduate university level. The dominant normative model of business ethics suggests that the aim of business ethics (including the teaching of business ethics) is to move businesspeople from an egotistic position to an altruistic position. According to the latter position, the greater good of society is served by unselfish, other-regarding action, instead of by the narrow, self-centred interests of individuals or corporations acting on their own behalf (i.e. egoism). In this paper, the dominant model is analysed and criticised by means of subjecting it to the question of whether it is at all possible to move people from one position to another through teaching business ethics. A second, related aim of this analysis and critique deals with the question of whether ethics (as taking up moral responsibility for one's actions) really entails a neat, linear model of change from position A to B. To arrive at a possible alternative model of teaching and "doing" business ethics, we explore some classic philosophical positions in which mixed signals are given regarding the status of egoism in ethics. This analysis will be applied to, and supported by, experience gained from teaching business ethics to accounting and management students at undergraduate level at the University of Stellenbosch.
\end{abstract}

Key words: Teaching business ethics, egoism, altruism, neoclassical economic theory, globalisation, complexity theory, complex ethics

\section{Introduction}

The motto in the title of this paper namely, 'They are all lies. Even Mother Theresa did it for herself', was lifted from an essay for business ethics, written by a group of third year business management students. When one analyses this motto, the underlying assumption that all

Johan Hattingh is a professor of Philosophy at the University of Stellenbosch and vice dean: Social Sciences in the Faculty of Arts and Social Sciences at the University of Stellenbosch. He specialises in applied ethics and teaches business ethics, engineering ethics and environmental ethics. In 2004 he became a member of The World Commission on the Ethics of Scientific Knowledge and Technology (COMEST) of UNESCO, and he has served on this commission as rapporteur since 2005.

Minka Woermann is a lecturer of Philosophy at the University of Stellenbosch. Her interests are in applied ethics, poststructural ethics and the ethics of complex systems. She is currently involved in teaching and researching on projects in the fields of business and professional ethics. Minka holds an M.A. in Philosophy and is busy with her Ph.D., entitled 'Critical complexity: deconstruction, complexity theory and the ethics of business.' actions by all people are basically undertaken to promote self-interest is identified. This implicit assumption is thought to hold even in cases of extreme self-sacrifice. Therefore, according to this view, not only is altruism a lie, but ultimately, so too is the message of ethics.

The aim of this paper is to demonstrate that this motto is indicative of a dominant model of thought regarding business and human action. This dominant model forms the background and context within which an almost cynical skepticism about business ethics is fostered - both in its practices and in its teachings. We shall begin by analysing the nature and the scope of this model. In order to achieve this, the general and specific assumptions and implications that underlie this paradigm, are explored. Next, an alternative model for understanding and teaching business ethics is introduced. This alternative model emphasises the need for engaging with current-day problems in a significant and practical manner. Lastly, our intention is to indicate how this alternative model undermines the simplistic dichotomy between egoism and altruism presupposed in the dominant model. In so doing, this dominant model is exposed as being based on a naive and out-dated assumption of what ethics is supposed to be, and also what ethics can 'do'.

\section{The dominant model}

The dominant model $^{2}$ that currently continues to inform thinking about ethics is characterised by a sophisticated, yet radical egoism. This form of egoism remains an implicit, and often unquestioned, premise in much of neoclassical economic theory, and is still widely adopted in business practice today. Examples of neoclassical economic theory include a) Adam Smith's 'invisible-hand argument' (Smith, 1985), which is presented as a crude form of Utilitarianism, where the sum of individual, self-interested acts ultimately supports the self-interest of society as a whole; and b) Milton Friedman's theory (Friedman, 1962; 1970), which argues for the complete separation of the economic and social spheres in business on the grounds of the promissory relationship between owners and managers of corporations. The ethical assumption that supports a free, unrestrained market economy is that people are basically driven by self-interest. In such an economy, market forces regulate conduct in such a way that society's best interests are served. This form of 'enlightened self-interest' nullifies the need for ethics. 
In light of this, ethics becomes an impotent concept - one that cannot benefit or transform society in any significant manner. Since ethics cannot easily be utilised proactively on an institutional level, its only value lies in its regulatory function, namely 'catching out the bad guy'. However, even when such a compliance-based approach is adopted, the law seems to perform this function more effectively than ethics. As such, ethics becomes primarily the concern of the individual, and amounts to the personal values and ideals of individuals. In other words, ethics is what people do in their private time.

There is, however, an alternative view, one which is also reflected in the dominant model, and which presents the inverse of the neoclassical argument based on individual, selfish behaviour. This argument is motivated on the grounds that the social cost of selfish behaviour is too high, and that the greater good is better served by altruism than by the sum of self-interested acts. Note that here too, the emphasis is on the individual, yet the work of ethics now entails moving individuals from self-interested, egotistical behaviour to selfless, altruistic behaviour. In this view, ethics has the idealistic and unattainable goal of turning immoral people into moral people. The manner in which this is achieved is either through an externallyorientated approach, with an emphasis on 'enframing' agents in a set of rules, codes of conduct etc; or through an internally-orientated approach aimed at instilling the correct values/virtues in individuals. However, this view of the dominant model is - as will be demonstrated in this paper - no less problematic than the view focused only on self-interested behaviour.

\section{Reactions to and perpetuations of the dominant model}

By exploring the dominant model in its totality, and by drawing on our experience of teaching business ethics to undergraduate students, we have identified three broad categories of responses by students to this model: Firstly, some students view ethics within the paradigm of neoclassical theory, and therefore embrace the cynical idea that ethics in business is unattainable. At its most cynical, these students feel that the only use of studying ethics is to better exploit others. This attitude is reflected in statements such as: 'ethics helps one to identify loopholes in the law'; 'the most successful businessperson is the one that can fake honesty'; and 'window-dressing ethics is a way of talking without the need for walking'. This model is equivalent to the immoral stance on ethics in business.

Secondly, many students embrace the idealistic idea that ethics is supposed to move us from selfish to selfless actions, i.e. they adopt the moral stance. As such, these students believe that courses in ethics will necessarily lead to ethical behaviour. Therefore, if these students do not turn out to be ethical later on in life, the law can better nail them, since they have passed a course in business ethics and are supposed to be ethical individuals.

The third category is the group of students that are sceptical about ethics, both in terms of its neoclassical assumptions and altruistic assumptions. In terms of neoclassicism, these students argue in the same vein as Smith and Friedman, believing that ethics goes against the grain of doing business. As such, market behaviour will always act as a general, constant deterrent to moral behaviour. In terms of the altruistic paradigm, skeptics question our ability to restrain self-interest, since it is unclear whether any practical or theoretical basis exists to justify the notion of a limited self-interest. These sceptics argue that if such a basis is appealed to, it is usually motivated either on subjective (i.e. personal) or external grounds (i.e. codes of ethics, or even legislation). This represents a typical amoral stance.

As teachers of business ethics, we reinforce the dominant model if we only emphasise self-centered action as the core problem in the cases that we discuss. For example, if we analyse studies such as the Enron case (Duska \& Duska, 2003) and the Ford Pinto case (Birsch \& Fielder, 1994; Applegate, 1993) only in terms of self-interested, egotistical behaviour, we ignore the larger contextual issues that make such unethical practices possible in the first case. Another way in which we reinforce the dominant model, is by concentrating only on individual ethics. This is typically done by emphasising examples of immoral business people, or, conversely, by promoting the values and virtues of 'individual ethical heroes', who resisted the onslaughts of 'the corrupt system'.

In conclusion, one finds the dominant model of ethics to be constituted by several modernistic assumptions of the neoclassical paradigm - many of which are insufficiently challenged - which reinforces this outdated model of ethics. Amongst the most important of these assumptions is the idea that humans are free and autonomous subjects. Assuming that humans are free and autonomous subjects, also implies that we are the authors of our own destiny; that we are in control of our own lives (or should be); that we are responsible for our own actions; and that we are accountable to all other rational human beings. The implication of this view is that knowledge is ultimately still a virtue ${ }^{3}$. In terms of ethics, this means that if I know what is right I will do the right thing, I will want to do the right thing, I will be able to do the right thing, and I will find universal acceptance for my actions and my reasons for them (since they are based on rational principles shared by all other rational agents).

\section{Challenges to the dominant model}

Many modern day realities challenge the assumptions implicit to the dominant model. The three most significant challenges emanate from the nature and 
structure of human agency today (e.g. corporate or collective action); the context of human agency today (e.g. globalisation); and, the interplay between the structure of human agency and context (e.g. corporations functioning within a global context).

In terms of the first challenge, namely corporate or collective action, two points serve to undermine the idea of individuals as autonomous, moral agents: Firstly, corporations are artificial constructions recognised in terms of law. Like humans, corporations have rights and responsibilities, as well as privileges and obligations (Shaw, 2008: pp. 163-164). This is a significant yet contentious point, since the idea of holding artificial entities accountable for moral or immoral behaviour is a debatable issue (pp. 164-165). For the purpose of this paper, we shall not review the different positions in this debate, except to state that the mere notion of assuming corporate responsibility already implies that moral action cannot only be viewed on the level of the individual. Secondly, groups of individuals act on behalf of corporations. This conjures up 'the problem of many hands' and yet again places the notion of individual moral agency (at least in a corporate context) under scrutiny (pp. 165-167).

The second challenge to the dominant model stems from the current context of human agency. Globalisation is often understood as a world-wide web of economic and technological efficiency. However, the distribution of resources is by no means uniform. Rather, the current situation is better characterised by the description of two worlds in one: namely, the connected and the disconnected ${ }^{4}$. Furthermore, due to the complex nature of the environment in which corporations operate, actions in one location frequently affect distant, unseen others in often unexpected ways. In other words, the environment creates non-linear interactions between the different role players. This implies that the reach of agency is global, whilst much of the acceptance of responsibility is still local. One reason for this is that non-linear interactions cannot be modelled in current decision-making models. Since self-interested activities by individuals and corporations often have unforeseen negative and perverse effects on visible and invisible stakeholders in local and distant contexts ${ }^{5}$, globalisation thus undermines neoclassical economic theory,

The third challenge to the dominant model refers to the interaction between corporations and globalisation; otherwise stated, the way in which corporations function within a global environment. Due to the increasing levels of competition and financial disparities between countries and corporations, many agents and institutions in developing countries now compete with each other to receive work. Competition often drives these agents, institutions and countries to accept work for pitiful sums of money, a phenomenon that is known as the race to the bottom'. This phenomenon nullifies ethical considerations. Furthermore, the enormous economic power of multi-national corporations (MNCs) begs the question of whether sovereignty still belongs to the state - especially in light of the fact that many of the large MNCs have more substantial annual turnover than the GDP of certain countries (Shaw, 2008: p. 159). The danger here is that corporations are not necessarily constrained by the same rules and conventions applicable to states. Therefore, self-interested activity in this context can have, and have already had, devastating effects on significant numbers of the world's population. Another point to bear in mind is that corporations function in a multicultural world. The assumption that universal agreement can be achieved regarding what is right and acceptable is highly problematic within this context.

All three of the above-mentioned challenges point to an overarching fact namely, we live in a complex world, and as such, neoclassical modernist assumptions are inadequate to ground ethical theory and respond to the problems of the day. In order to overcome the limitations of the dominant model, the complexity of the current day situation needs to be understood, addressed and incorporated in notions and applications of ethics. In the context of this paper, we specifically address the implications of complexity for the environment, the corporation, the individual and ethics.

\section{A complex ethics}

A complex ${ }^{6}$ environment (such as the one in which we function) is constituted by webs of relational elements, where the relations between elements are characterised by non-linear, dynamic interactions (Cilliers, De Villiers \& Roodt, 2002: pp. 9-10). This definition of a complex environment has several implications for both corporations and individuals within this environment (pp. 10-13): Firstly, if corporations and individuals function as webs of relational elements, which interact with other webs of relational elements, we can conclude that corporations and individuals are open systems. Secondly, in order to survive in a complex environment (constituted by dynamic, non-linear interactions), corporations and individuals should be flexible to adapt to changing circumstances. However, corporations and individuals are also not random collections of elements, but are uniquely organised. This unique organisation is the product of the system's history (or memory of previous interactions). This implies that corporations and individuals should be flexible enough to deal with the inherent uncertainty that characterises complex environments, yet sufficiently robust to retain their own identity. Thirdly, to suggest that individuals are relationally constituted (and therefore, open, emergent systems) is to concede to the point that individuals, far from being a-temporal, universal and autonomous agents, are contextual, embedded and historical beings, 
constituted by the choices they make within their embedded and relational situation. As such, individuals are never totally whole, free or transparent, but rather become over time. The above characteristics of complex systems serve to undermine modernistic assumptions of the individual upon which the dominant model of ethics relies.

The ethical implications of such an alternative model, which takes the complexities of our worldly situation into account, do not amount to ethical impotence, as is the case in the dominant model. Rather, complexity calls for a heightened sense of responsibility. This is because no universal norms can exist within a context of uncertainty, and, therefore, decisions and actions must always be argued for (Cilliers, De Villiers \& Roodt, 2002: p. 16) Within this immanent context, descriptions of ethicallyproblematic situations are also never neutral (p. 13), so our justifications for our choices are also contextual, embedded, historical and limited.

Furthermore, our choices, actions and justifications do not only impact upon our immediate environment, but also affect other open systems and reverberate through these systems, ultimately feeding back into our own 'system' again. Since our choices and justifications are not neutral, and since they affect other systems or people, these choices and justifications are characterised by an ethical-political dimension. Another way of saying this is that an embedded subject is always already in the realm of ethics (p. 11), which means that we cannot escape from making difficult choices on the basis of considerations which themselves cannot be ultimately and finally justified. To appeal to autonomous moral agency and homogenised ethical justifications based on a-temporal and fixed meta-rules, is to violate the subject in question. This is because such appeals presume that we are in a position to fully know what subjecthood entails, and therefore also know what the correct way of acting towards, and treating, one another entail (p. 12). This holds implications not only for decisions made in the personal sphere, but also for all the strategic and operational decisions made by businesspeople, as these decisions cannot but influence the lives of others.

A complex ethics that is sensitive to the complexity of the world we live in, provides us with potent arguments against the reactions of students and businesspeople alike, who see no value in 'doing' ethics. Furthermore, a complex ethics tempers the reactions of cynics (immoralists), idealists (moralists) and skeptics (amoralists). It undermines the cynical position by showing that - far from being impossible - ethical reflection is unavoidable, given that we are always in the realm of ethics. If ethics is concretised in real-time, the naivety in the idealists' belief that ethics can overcome egoism and lead us to a neat, and self-contained altruism, surfaces strongly. A complex ethics also illustrates that decision-making, though unavoidable, is never complete or finally justifiable in the absence of meta-rules and autonomous subjects. We always have to revisit and adjust our incomplete and limited justifications as we move on in time and enter into new contexts. Lastly, complex ethics overcomes the sceptical position - which asserts that ethics goes fundamentally against the grain of doing business - by highlighting the interdependence of open systems in a complex environment. In other words, business cannot isolate itself from society as if it is a closed system with its own set of rules.

\section{Conclusion}

In conclusion, the implications of complexity theory for teaching business ethics are briefly investigated. Though we agree that ethical reflection entails critically analysing, responding to, evaluating and problematising our assumptions, actions and justifications, we argue that it is necessary to take this view further. A complexity perspective moves us beyond traditional critical thought, and may assist us to foreground and criticise the prejudices and preconceptions that underlie much of what we generally accept without question. In this model, the work of business ethics cannot be to merely move people from a neat model of egoism to a neat model of altruism. Rather, the purpose of business ethics is to help students understand that both egoism and altruism, for example, can be problematic positions. The work of business ethics thus seems to be to identify which relations and interactions between agents and systems - including processes of decisionmaking, structures and institutions - impact negatively or positively upon a specific ethically-problematic situation. Accordingly, we should shift our focus from agents to the constituents of agency within a specific local and global context. In order to achieve this, an approach that emphasises the context in which both formal and informal systems are continued (rather than a strictly theoretical or agent-orientated approach), should be employed in teaching business ethics.

In light of this, the question of whether Mother Theresa's actions are all lies, seems to be the wrong question to ask: Implicit in this statement are much more radical questions that ethicists need to address namely: Why is this motto accepted as the truth about ethics and used as an argument against ethics? Which prejudices and preconceptions underlie this motto? Why are these prejudices and preconceptions left unchallenged? And most importantly, is it not time for an understanding of business ethics that focuses on the context of ethical decision-making and that always, already places the individual in the realm of ethical thought? Such a conception of ethics will hopefully lead to a constant and critical interrogation of the manner in which we make decisions, provide justifications and act on our convictions. 


\section{References}

Applegate, P. (1993). 'GM is held liable over fuel tanks in pickup trucks'. New York Times, February 5.

Aristotle. (1980). The Nichomachean ethics (revised edition). (trans. D. Ross) Oxford: Oxford University Press.

Bauman, Z. (2000). Globalization: The human consequences. New York: Columbia University Press.

Birsch, D. \& Fielder, J.H. (Eds.) (1994). The Ford Pinto case: A study applied in ethics, business and technology. Albany, NY: State University of New York Press.

Cilliers, P. (1998). Complexity and postmodernism. London: Routledge.

Cilliers, P., De Villiers, T. \& Roodt, V. (2002). 'The formation of the self. Nietzsche and complexity'. South African Journal of Philosophy, 21(1), 1-18.

Duska, R.F. \& Duska, B.S. (Eds.) (2003). 'Enron, Arthur Anderson, and the Financial Markets: A chronology of Wall Street Journal articles in accounting ethics.' Accounting Ethics. Oxford: Blackwell.

Friedman, M. (1962). Capitalism and freedom. Chicago: Chicago University Press.

Friedman, M. (1970). 'The social responsibility of business is to increase its profits.' New York Times Magazine, September 13, 33, 126.
Kant, I. (1988). Grounding for the metaphysics of morals. Indianapolis: Hackett.

Shaw, W.H. (2008). Business ethics. Belmont, CA: Wadsworth/ Thomson Learning.

Smith, A. (1985). The wealth of nations. New York: Modern Library.

Thompson, J. (1990). Ideology and modern culture. Cambridge: Polity Press.

White, T.I (1993). Business ethics: A philosophical reader. New York: MacMillan.

Address correspondence to: Johan Hattingh or Minka Woermann

Department of Philosophy Stellenbosch University Private Bag X1

Stellenbosch 7602

Tel: +27 (0)218082418

Fax: $+27(0) 218083556$

e-mail:jph2@sun.ac.za orminka@sun.ac.za

(Endnotes)

$1 \quad$ Paper read at the $6^{\text {th }}$ Annual Conference of BEN-Africa, Bellville, South Africa, July 2006.

2 For an overview of the dominant model see:

Shaw, W.H. (2008). Business ethics. Belmont, CA: Wadsworth/Thomson Learning. Chapters 2, 4 and 5.

White, T.I (1993). Business ethics: A philosophical reader. New York: MacMillan. Chapters 1 and 2.

3 See: Kant, I. (1988). Grounding for the metaphysics of morals. Indianapolis: Hackett; Aristotle (1980). The Nichomachean ethics (revised edition). (trans. D. Ross) Oxford: Oxford University Press.

4 See: Bauman, Z. (2000). Globalization: The human consequences. New York: Columbia University Press.

5 See: Thompson, J. (1990). Ideology and modern culture. Cambridge: Polity Press.

6 See: Cilliers, P. (1998). Complexity and postmodernism. London: Routledge 
Reproduced with permission of the copyright owner. Further reproduction prohibited without permission. 